\title{
Autonomy and interdependence: Quandaries in research ethics
}

\author{
Bolatito Lanre-Abass \\ Department of Philosophy, University of Ibadan, Ibadan, Nigeria; bola_abass@yahoo.com
}

Received 1 December 2011; revised 4 January 2012; accepted 14 January 2012

\begin{abstract}
The autonomy of research participants is crucial in research ethics without which it will be difficult to carry out research. Central to the concept of autonomy is the debate on whether the cultural norms of individuals (particularly women) should be given priority in settings where these norms require that researchers should go through male heads such as husbands and traditional leaders. This paper examines issues relating to the autonomy of women in research ethics. It highlights the far-reaching implications of autonomy for women participating in research using Islam as a religion and Africa as case studies. The paper takes a look at what obtains in Ghana and Nigeria as African countries with diverse religious sects highlighting at the same time the extent to which women are autonomous in some Islamic parts of India and Pakistan. The paper stresses that in spite of certain factors limiting the autonomy of women in Africa and Islam, there is need for a more robust account of autonomy. It takes a relational approach to autonomy concluding at the same time that the best way to do bioethics is to be culture-sensitive.
\end{abstract}

Keywords: Autonomy; Interdependence; Research Participants; Relational Autonomy; Rights; Culture and Dignity

\section{INTRODUCTION}

Autonomy is a guiding principle for contemporary research along line with beneficence, non-maleficence and justice. The requirement for research subjects' autonomy becomes imperative in the light of various forms of abuses in research ethics. This paper examines various issues surrounding the autonomy of women in research ethics both in Africa as a continent and in Islam as a religion. It focuses on Ghana and Nigeria as two African countries that are not predominantly religious and at the same time looking at the autonomous nature of women in some Islamic parts of India and Pakistan. It argues that the Western account of autonomy is so superficial because according to Beauchamp and Childress (2001), to restrict adequate decision-making by research subjects to the ideal of fully or completely autonomous decisionmaking strips their actions of any meaningful place in this practical world, where people's actions are rarely, if ever, fully autonomous [1].

The paper highlights the apparent tension between autonomy and interdependence. It sees the need not only to resolve the conundrum in research ethics but also to be critical of the atomistic assumptions of personhood that is at work in bioethics. It stresses that in everyday life, human beings are relational beings, hence autonomy should be thought of as essentially relational. The paper concludes by emphasizing that great benefits could be derived, if culture and traditions are respected when conducting scientific researches.

\section{CONCEPTUALIZING THE PROBLEM}

Autonomy, more than any other word and concept in research ethics, has crystallized the contemporary emphasis on research ssubjects' rights. Autonomy is often characterized as some form of self-determination. According to Catriona Mackenzie and Natalie Stoljar (2000):

In bioethics, autonomy is often equated with informed consent. In rational choice theory, autonomy is equated with voluntary, rational choice. In other contexts, for example, within liberal political theory, autonomy is considered to be an individual right. For liberals of a libertarian persuasion, the right to autonomy is construed as a negative liberty, a right of the individual to freedom from undue interference in the exercise of choice (moral, political, personal and religious) and in the satisfaction of individual preferences. For Rawlsian liberals, autonomy is understood in Kantian terms as a capacity for rational self-legislation and is considered to be the defining feature of persons [2].

Dyson and Moore (1983) define autonomy as "the ability to obtain information and to use it as the basis for 
making decisions about one's private concerns” [3]. In feminist discourse, autonomy is defined as 'the degree of women's access to and control over material resources including food, income, land, and other forms of wealth and to social resources including knowledge, power, and prestige within the family, in the community, and in the society at large [4].

Beauchamp and Childress (2001) highlight the traits of an autonomous person as including the capacities of selfgovernance, such as understanding, reasoning, deliberating and independent choice. To respect an autonomous agent therefore is to acknowledge that person's right to hold views, to make choices and to take action based on personal values and beliefs [5]. Emphasizing the place of autonomy in bioethics, James F. Childress (1990) explains that the ideal of autonomy must be distinguished from the conditions for autonomous choice. According to him:

It is important for the moral life that people be competent, be informed and act voluntarily. But they may choose, for example, to yield their first order decisions (that is, their decisions about the rightness and wrongness of particular modes of conduct). For example, they may yield to their physicians when medical treatment is proposed or to their religious institutions in matters of sexual ethics. Abdication of first order autonomy appears to involve heteronomy, that is, rule by others. However, if a person autonomously chooses to yield first-order decision-making to a professional or to a religious institution, that person has exercised what may be called second order-autonomy [6].

Talking about autonomy, Gerald Dworkin (1976), explains that autonomy includes both authenticity and independence or more specifically, procedural independence. Persons possess authenticity when their actions are their actions, that is, when they accede to and identify with, whatever motivates them to act. What establishes authenticity is a person's acceding to and identifying with the motivation. On the other hand, persons possess procedural independence when they accede to, or identify with whatever motivates them to act without being victims of other person's manipulation or deception. To be autonomous in this regard is to be one's own person, to be directed by considerations, desires, conditions and characteristics that are not simply imposed externally upon one, but are part of what can somehow be considered one's authentic self [7]. In this regard, autonomy is an irrefutable value because the opposite which involves being guided by forces external to the self marks the height of oppression.

Although Dworkin stresses that autonomy is a fundamental value by giving a deeper understanding of the concept, he however used the concept to set guidelines for behaviour control. He rejects the traditional notion of autonomy, which associates the concept with a person acting according to self-selected rules. Dworkin explains that because of environmental influences and biological endowments, persons do not "self-select" their convictions, motivations, principles, beliefs, desires, habits, emotions, and so on, things he called "first-order considerations". Putting Dworkin's position in perspective, Ronald Yezzi (1980) explains that a self-selecting or selfchoosing in isolation from these influences and endowments is quite simply impossible. Persons can only make "second-order judgments" in which they reflect upon and formulate attitudes toward first-order considerations[8]. Thus, they can reflect and form preferences accordingly. To use Dworkin's example, they have desires to smoke (a first-order-consideration) but they also can desire that they desire to smoke (a second-order judgment). Within this process of making second-order judgments resides human autonomy. Moreover, this autonomy is sufficient for persons to take moral responsibility for their actions.

Consequent upon these divergent definitions, Freidman (2003) identifies certain characteristics that are repeatedly associated with autonomy. According to Freidman:

In general parlance, autonomy is a capacity, an activity or exercise. More specifically, it is the capacity to make decisions for oneself based on one's own values and goals arrived at through processes of self-reflection. This capacity is then demonstrated through behaviour that is based on these values and is exercised under certain necessary conditions. These conditions include opportunities for meaningful choice and the ability to act without incapacitating, coercion or manipulation. While autonomy can be defined both procedurally and substantively, it is increasingly defined in a content neutral manner which emphasizes only that the opportunity for autonomy be ensured, while the individual chooses if, when, and how to act autonomously [9].

Churchill (2005) identifies two components of autonomy. First, it means treating subjects as free moral agents by actively promoting their independent reflection, deliberation and decision making. This entails not only fulfilling the legal obligation of providing information necessary to an informed choice but also actively encouraging and enabling subjects to deliberate on the basis of their own values. Second, respecting autonomy in research subjects means, quite simply, honoring the choices they make. No weighing, balancing or adjudication is required or appropriate [10].

However, the concept of autonomy has little force if it places subjects in a passive role and makes their values and opinions subject to adjudication by some higher authority. Therefore, any adequate principle of autonomy must begin with the conviction that competent patients and subjects already possess the rights to decide for 
themselves. In research, the deliberative process is lodged with research subjects even though a robust deliberative process can only be achieved with the help of investigators, investigators do not have decisional prerogatives [10]. These belong to research subjects and only to them as long as they are adults and possess decisional capacity. Commenting on the roles of the investigator, Churchill (2005) opines that "the investigator's role is a critical one, for it involves information giving and initiation of a reflective process that will strengthen subjects" decisional abilities. This enables these subjects to bring to decisions about participation not only reliable information about the research protocol but also the personal life values that are germane to their choices. He further strengthens his position by explaining that:

The main point here is that investigators should not be viewed as morally empowered to "give weight" to subjects' choices. Subjects are not given authority for selfdetermination by investigators. Subjects possess this authority because they are persons. This is what respect for persons must mean if it is to entail respect for autonomy. The appropriate action for investigators is, therefore, not to give authority to subjects' values, but to acknowledge subjects' rights to independent decisional authority based on their own values. Moreover, investigators are obligated not only to acknowledge the right of independent choice but to promote, to the extent possible, that right in subjects for whom deliberation for choices may be compromised by illness, uncertainty, fear, or lack of information. To do less is to fail to respect them as persons, by failing to help them "overcome dependence" [10].

To achieve a more meaningful exercise of autonomy, there is need to move beyond the Western conceptualization of autonomy to a more robust idea of autonomy. A more robust idea of autonomy according to Churchill (2005), recognizes the asymmetry of power between investigator and subject; it responds to the social nature of the exercise of autonomy [10]. Even if individuals are free to make their choices, it is not a steady capacity with which individuals are born, but a fragile social achievement. We need to be assisted by family and friends if we are to be truly autonomous persons. We become autonomous through the enabling actions and support of others. This is important in the context of research because it implies that subjects must be empowered through their relationship with investigators, that is, through investigators' willingness to discuss, disclose, and reflect with subjects on the substantive matters of research participation, including the subjects' values.

Churchill further explains that:

The absence of an enabling duty for researchers bespeaks a view of persons that is unrealistic because it is too atomistic. It fails to recognize the crucial place of social supports, especially the support of the researcher for the subjects, in making choices that are authentic and genuine. Thus, a strong, enabling dimension to the autonomy principle is required, not only because of the vulnerability of subjects, but in order to respect the social nature of autonomy [10].

Although respect for autonomy is an important principle for subjects/participants in research, too much stress on autonomy can lead to an isolation of the subject and even distort people's understanding of the way individual decisions are embedded in web of relationships and familial values. Also, stressing individual autonomy to the exclusion of other values can do real harm to families [10].

Subjects sometimes have unrealistic expectations of directly benefiting from participation in research, even very early in research in which direct benefit is not intended. Given this misconception, the hazard is not that subjects will be isolated or will harm others through their choices, but that their choices will be overwhelmed by these unfounded expectations and by the other powerful forces driving medical research. Churchill, (2005) identifies these additional forces as including "the growing commercial investments in human research, the scientific and monetary ambitions of researchers and their institutions, and the career and pecuniary interests and enrollment coordinators and others involved in recruiting and maintaining subjects' participation” [10]. Given these pressures and the possibilities for therapeutic misunderstanding, a more robust sense of autonomy is essential to research ethics.

The call for a more robust conception of autonomy becomes imperative because if autonomy is social in nature, then the quandary between being autonomous or interdependent is more likely to be resolved. Although some critics have alleged that appeals to the community, public welfare or social good have occasionally usurped individual rights and decisional prerogatives in the name of scientific progress, seeking a social approach to autonomy will mean appreciating the multidimensional character of persons, their culture and experiences [10].

\section{KANT AND MILL ON AUTONOMY}

According to one philosopher, (Immanuel Kant, 1959), respect for autonomy flows from the recognition that all persons have unconditional worth, each having the capacity to determine his/her own destiny. To violate a person's autonomy is to treat that person merely as a means, that is, in accordance with others' goals without regard to that person's own goals. Undoubtedly, Kant's arguments, though not explicitly mentioned, rely on an understanding of the concept of autonomy. For Immanuel Kant, autonomy is the ability of rational beings to choose their own actions by means of reason and absence of the du- 
ress of outside influence [11]. Under his kingdom of ends formula, Kant describes everything as having either a price or a dignity which is inherently above price. Man's rational nature is a dignity, because of the ability to participate in morality. The rational nature gives rise to the presence of autonomy, which in turn further enables the freedom of the rational nature. It is precisely because of the inextricable intertwining of autonomy and the dignity of the rational nature that Kant regards autonomy as being of unconditional value [12].

However, Kant's humanity formula also called the end in itself formula is a moral code stating that we should consider all rational creatures to be ends in themselves rather than merely as a means to some end. This means that we must treat all human beings according to the dignity inherent in the rational nature of man. He later distinguishes between positive and negative compliance of this formula. Negative compliance is not acting such that we use others as a mere means. Positive compliance by contrast is acting such that we attempt to better the situation in order to cultivate the humanity of all rational beings involved [12]. Central to Kant's idea here is that we must consider humanity, dignity or rational nature as that which is of greatest and unconditional value.

Another philosopher, John Stuart Mill (1977), emphasizes the "individuality" of autonomous agents. He argued that society should allow individuals to develop according to their convictions, as long as they do not interfere with a like expression of freedom by others. He puts forward a principle meant to govern absolutely, the dealings of society with the individual in the way of compulsion and control. The principle is that the sole end for which mankind are warranted individually or collectively in interfering with the liberty of action of any of their member, is self-protection [13]. Therefore, the only purpose for which power can be rightfully exercised over any member of a civilized community against his will is to prevent harm to others. Mill recognizes the fact that we are sometimes obligated to seek to persuade others when they hold false or ill-considered views. According to him:

His own good, either physical or moral is not a sufficient warrant. He cannot rightfully be compelled to do or forbear because it will be better for him to do so, because it will make him happier, because in the opinion of others, to do so would be wise, or even right. There are good reasons for remonstrating with him or reasoning with him or persuading him or entreating him, but not for compelling him or visiting him with any evil, in case he does otherwise. To justify that, the conduct from which it is desired to deter him must be calculated to produce evil to someone else. The only part of the conduct of anyone for which he is amenable to society is that which concerns others. In the part which merely concerns him, his independence is, of right, absolute. Over himself, over his own body and mind, the individual is sovereign [13].

The implication of the above is that, the individual ought to be free to do what he/she wishes unless there are good reasons for preventing him/her from acting freely. The only reason provided by Mill is that of likely to harm others.

\section{THE NEED FOR ETHICS IN HUMAN RESEARCH}

Many disciplines, institutions and professions have norms of behaviour that suit their particular aims and goals. These norms also help members of these professions to coordinate their actions or activities and to establish public trust in their various professions. For instance, ethical norms govern conduct in medicine, law, engineering, and business. Ethical norms also serve the aims or goals of research and apply to people who conduct scientific research or other scholarly and creative activities. There is a specialized discipline known as research ethics which studies these norms.

David and Resnik (2010) identify reasons why it is important to adhere to ethical norms in human research. According to these people, ethical norms promote the aims of research such as knowledge, truth and avoidance of error. Also, since research often involves a great deal of cooperation and coordination among many different people, in different disciplines and institutions, ethical standards promote the values that are essential to collaborative work such as trust, accountability, mutual respect and fairness. Again, many of the ethical norms help to ensure that researchers can be held accountable to the public. Furthermore, ethical norms in research also help to build public support for research. People are more likely to trust research project if they can trust the quality of and integrity of research. Lastly, many of the norms of human research promote a variety of other important moral and social values such as social responsibility, human rights, animal welfare and compliance with the law and health safety [14].

However, it is important to stress that ethical lapses in research can significantly cause harm to human and animal subjects, students and the public. For instance, if a researcher fabricates data in a clinical trial, this may harm or even kill patients. Also, a researcher who fails to abide by regu- lations and guidelines relating to radiation or biological safety may jeopardize his health and safety or the health and safety of other staff and students.

Given the importance of ethics for the conduct of research, various codes have been designed for research ethics. Many different professional associations, government agencies and universities have adopted specific codes, rules and policies relating to research ethics. 
Some ethical principles that various codes address are: honesty, objectivity, integrity, carefulness, openness, respect for intellectual property, confidentiality, responsible publication, responsible mentoring and respect for colleagues, social responsibility, non-discrimination, competence, legality, animal care, and human subjects' protection [15].

Pointedly, although codes, policies and principles are very important and useful like any set of rules, they do not cover every situation. They often conflict and they require considerable interpretation. It is important for researchers to learn how to interpret, assess and apply various research rules and how to make decisions and act in various situations. The vast majority of decisions involve the straightforward application of ethical rules.

\section{THE AUTONOMY OF WOMEN IN SOME SECULAR AND RELIGIOUS COUNTRIES}

Until recently, in many African societies, women, compared to their male counterparts are placed in subordinate positions by custom, in the family, the economy and the polity. This has had implications for the ways African women are viewed and regarded. This unequal social arrangement has been questioned by many feminists who describe many African societies as patriarchal. For these feminists, the stereotype perception of women has also shaped their experiences making it difficult for them to move beyond domination [16].

Gender stereotypes are bipolar in the sense that women and men are perceived to have opposing personal qualities. The core meaning of stereotypic beliefs about the sexes is best captured by distinctions such as hard/ soft, active/passive, culture/nature, reason/emotion, visible/invisible and so on. Stereotype perception of women is continuous with stereotyping of any sort such that in many African societies, women are disadvantaged by customs, religion and the polity.

However, various factors are identified as limiting the autonomy of African women. Apart from low level of education which consequently affects the level of awareness of women in some traditional African societies, sociologists such as Omonzejele (1988) have identified the payment of bride price as basic among the factors that limit the autonomy of women to participate in research in Africa. Bride price is the foundation of marriage rites in most African countries and the moment a woman gets married, she is made to concede most of her rights associated with the attainment of full-age to her husband and his family members through the payment of bride price. The payment of bride-price gives husbands and their family members controlling influence over married African women. It gives family members the impression of having purchased their wives. Hence the bride- price place African women in an inferior power relationship in marital union in many African countries [17]. For instance, in Nigeria, under the customary law, a black woman remains a legal minor all her life under the custodianship of her father, husband, or eldest son as her life progressed from childhood to marriage and widowhood to old age [18].

Normally, legal minors do not make far-reaching decisions and enlisting them in clinical research could be far-reaching. If so, many African women would need to secure permission/approval from their husbands before enrolling in clinical research. The same applies to an adult female that is unmarried. What this implies is that if researchers were to operate within the ambit of the Nigerian constitution, such researchers cannot enlist women without the approval of their fathers or male guardian [19].

Omonzejele further explains that the bride price and the customary law place women in an inferior power relationship in many African countries and this practice of male superiority is supported by native laws and customs tenable in such countries. This unequal relationships means that African women are marginalized in terms of giving first person voluntary informed consent, as they are required to get approval from their husbands before they could enlist in research [19].

Tindana, Kass and Akweongo (2006) carried out a study in Kassena-Nankana district of Northern Ghana (an African country), on the extent to which women can assert their autonomy in terms of giving first person voluntary informed consent when participating in research. These researchers describe the status of women in the Kassena-Nankana district of Northern Ghana as bleak in view of the social norms that give men "gate keeping" roles in households and compounds. In this district, the practice of consulting male leaders and household male heads about any new activity in the community, including research has been a long-established one. All the female respondents said they consulted their husbands before participating in a study, yet they gave different accounts about the extent to which their husbands' wishes affected their own decision concerning their participation. Below are some of the responses of these women.

First female respondent: "I will go and tell my husband that VAST people have come to ask me to join their study and so I want to let him know about it and if he says I should go, then I will go, but if he refuses, I won't go. That is why when he agrees I always come and join them."

Second female respondent: "I discussed it with my husband and he agreed for me to participate and that was why I took part in it.”

Third female respondent: "I make that decision and then my husband will also agree and then he will also ask 
me to participate. If I don't want to participate, my husband cannot force me to participate" [20].

Central to the three female respondents is the fact that their husband's permission to participate or not to participate is likely to influence the wife's decision and consequently compromising her autonomy. It is important to stress here that Nigerian women are not better off than their Ghanaian counterparts in terms of taking decisions. Hence what applies to a typical Ghanaian woman is also applicable to any Nigerian woman.

On the religious level, a whole chapter of the Qur'an (An-Nisa) is devoted to issues relating to women. The introduction to this chapter stresses that "women should be held in honor and their rights recognized in marriage, property and inheritance; this principle of goodness should be extended to all human beings, great and small" (Q 4: 15 - 42). There are also Qur'anic injunctions on the rights of women. For instance, Q4: 1 - 14 explains that "all mankind are one and mutual rights must be respected: the sexes must honor each other; sacred are family relationships". Similarly, Q4: 19 say "live with women on a footing of kindness and equity”. Again, Q4: 127 - 152 explains that "justice to women and orphans is part of religion and the fear of Allah. Hence women and orphans must be fairly dealt with. Faith must go with justice, sincerity and moderation in speech".

Unfortunately, some of these Qur'anic injunctions are often misinterpreted. For instance, Q: 28: 229 which says that "women shall have rights similar to the rights against them according to what is equitable; but men have a degree (of advantage) over them” and Q4: 34 "men are the protectors and providers of women because Allah has given one more (strength) than the other and because they support them from their means" are often misinterpreted. Words such as "having a degree over them, protectors and providers" are often interpreted as "initiator in affairs". This misinterpretation is evident in some Islamic regions of Pakistan and India. It is as a result of this that many Islamic feminist are critical of the content of Muslim family laws and the ways these laws restrict women's human rights and privilege men. They disagree that Islam is responsible for this, arguing that the Qur'an has been interpreted in patriarchal and often misogynistic ways over the centuries and even in recent times, that Sharia (Islamic-religious-based-law has been misunderstood and misapplied and that both the spirit and the message of the Qur'an have been distorted. For these feminists, what appears as God's law is in fact human interpretation [21].

Throwing more light on the condition of women in many Islamic countries, Offenhauer (2005) explains that the legal systems under which women live in Islamic countries are mostly dual systems. They consist, on the one hand, of civil law, which is indebted to Western legal systems and on the other hand, of Islamic family law, which is mainly built upon Sharia [22]. The civil law as well as the constitution of many countries provide for equal rights between women and men. However, Islamic family law as variously manifested in many Muslim countries poses obstacles to women's autonomy. In some Islamic regions of Pakistan, and India, women occupy a separate and distinctive position that effectively denies them education and autonomy. Muslim women in these regions have been described by Jejeebhoy and Sathar, (2001) as having relatively little autonomy or freedom of movement, limited inheritance rights in practice, and limited opportunities for control over economic resources.

According to Jejeebhoy and Sathar:

After marriage, a young woman is expected to remain largely invisible to outsiders and under the authority of her husband's family. She has little say in domestic decisions and little freedom of movement. The only means available to enhance her prestige and even security in her husband's home is through her fertility, and particularly the number of sons she bears [23].

Jejeebhoy and Sathar carried out a study on the autonomy of women in Pakistan and India. Women responded in different ways to the extent to which they can assert their autonomy in terms of giving first person voluntary informed consent. Their responses vary form region to region

First female respondent: "We do not make decisions. The husband is responsible; after him come the fatherin-law and then come the brother of the husband" (Muslim woman, central Punjab province, Pakistan).

Second female respondent: "In our village, the woman does not have any value, so most of the decisions are taken by men only”. (Brahmin, Pratapgarh district, Uttar Pradesh Muslim woman, North India).

Third female respondent: "We do not have any right to make decisions. The one who is uneducated, what decision could she take? She could only fight and quarrel. So it is right that the man alone takes decisions". (Jat, Meerut district, Uttar Pradesh Muslim woman, North India) [23].

Tamilian women, another part of Pakistan, in contrast, are more involved in decision making and are also more likely to believe that they are entitled to this authority: "Decisions should be taken jointly. A good decision can be made only when taken together-three-quarter of the time, decisions are taken by men and one-quarter of the time, they are taken by women and men together". (Scheduled caste, Ramnath Puram district, Tamil Nadu Muslim woman, South India) [23]

These findings suggest that the cultural contextoperationalized here by region-influences the factors associated with autonomy, hence the needs for context 
specific measures of women's autonomy.

Surprisingly however, critics such as Imam Hashim (1999) view these cultural factors as one of the factors limiting the autonomy of many Muslim women. Hashim identifies other factors limiting the autonomy of Muslim women first among which is the significant gap between what the Qur'an says regarding the autonomy of women and the manner in which its teachings are practiced. Secondly, there is failure on the part of women themselves to draw upon the rights of women as stated in a source considered to be divine and difficult to refute. Lastly, there is the problem of interpretation in which people who draw upon Qur'anic injunctions on the autonomy of women misinterpret passages to suit personal purposes [24].

\section{RECONSIDERING THE AUTONOMY OF WOMEN IN AFRICA AND ISLAM}

The limitations placed on the autonomy of most African and Muslim women call for the need to reconsider the autonomy of women in Africa as a continent and Islam as a religion. The Qur'an lays down significant rights for women, of which they are often unaware, but which can be drawn upon to address and improve their circumstances particularly their capacity to determine whether or not to participate in research. Steps towards achieving this have been highlighted by many Muslim feminist scholars.

First, educating Muslim and African women about their rights as contained in the Qur'an or the constitution of their country. This might prove an effective means of raising the awareness of Muslim and African women participating in research. This should be coupled with providing enabling atmosphere for them to make independent decisions irrespective of the practice of bride price. Promoting women's knowledge of their Islamic and constitutional rights become more important especially when one considers the frequency with which politico-religious groups cite Islamic and constitutional laws applied in some Muslim and African countries to support their own demands for more stringent and discriminatory Islamic and legal laws [25] or the manner in which Muslims are often misled by self-ordained Muslim divines [26].

There is also need to re-interpreting the purpose of African bride price as a profession of love, similar to the wedding ring in Western context. "When African and Muslim women realize that they could assert their autonomy in terms of giving first person voluntary informed consent as independent research subjects without the drawbacks associated with the payments of bride price, such autonomy will inevitably snowball into other spheres of life" [27].

Closely related to the above is the need to re-inter- preting Qur'anic injunctions. Recently, Muslim activists and feminist scholars have made efforts to reinterpret Islamic sources, suggesting that these can be read as fully supportive of equal human rights for all. The strategy involves returning to the Qur'an and conducting a study of the value system presented in the holy book. Their first point is that we most look to the Qur'an, not the other Islamic sources such as the Hadith, the Sunna and the Shariah for guidance [28]. The Hadith and Sunna are commentaries on the prophet's life, tradition and sayings while the Shariah refers to laws created in the first centuries after the prophet's lifetime [29]. All these sources are the outcome of human understandings of the Qur'an, which are influenced by the context in which they were conceived. Because this was an era which was organized hierarchically and patriarchally, these sources inevitably reflect this reality and the identity of the commentators who were overwhelmingly men [30].

It is important to point out here that the experiences of Muslim and African women differ across cultures and countries. Therefore, one cannot prescribe some form of universal formula to overcome the constraints they face; strategies adopted must respond to their contextual constraints. It is in the light of this that this paper stresses that researchers in particular and bioethics in general should be culture-sensitive

\section{BIOETHICSAND CULTURE-SENSITIVITY}

Although different anthropological, sociological and medical definitions have been provided on the concept of culture, it is defined by Olweny (1994) "as the sum total of the integrated patterns of knowledge, beliefs and behaviour of a given society" [31]. Cultural groups share thoughts, communication styles, ways of interacting, views of roles and relationships, values, practices and customs. Although culture is related to race and ethnicity, their domains cannot be superimposed. Hence it can be said that culture refers mainly to the social while race and ethnicity refer to the socio-biological domains. Factors such as socioeconomic status, educational level, language, geographic areas, urban versus rural contexts, religion, gender, sexual orientation, occupation and disability also define culture [32]. All these different elements of culture according to Kagawa-Singer, (2003) integrate as the woven thread of a tapestry to perform integrative and prescriptive functions, whose ultimate goal is to ensure the survival and well-being of individual member [33].

Culture is dynamic, interdependent and fluid. It evolves from within as well as under the reciprocal influence of other cultures. Individual persons or groups do not always conform to their own culture. Dissent has always been present in different cultures and it has greatly con- 
tributed to the progress of humankind. Members of different racial, ethnic and cultural groups undergo assimilation and acculturation [33]. Progressive exposures to global communication and increasing demographic mobility have contributed to profound cultural changes in contemporary societies. Yet it would be a mistake to ignore the fact that cultural identity today goes well beyond geographic and ethnic boundaries [34].

Antonella Surbone (2004) identifies three ways in which culture contributes to our identity. First, it provides us with a reference framework to interpret the external world and to relate to it. Culture influences how we perceive diseases, disabilities and sufferings, how we express our concerns about them, how we relate to individual physicians and to the health-care system. Secondly, culture helps us make sense of what is happening to us. Lastly, culture acts as a facilitator at special times of trial when we intensely need to rely on our sense of self and of connectedness [35].

However, Surbone cautioned that the importance of cultural influence on our personal identity should not be conceived in a deterministic way, as this will only reinforce prejudicial and stereotypical attitudes that inevitably culminate in more or less overt forms of discrimination [35]. She stresses that "cultural identity" is not a substitute for "personal identity". The two do not coincide neither are they collapsible. According to her, "personal identity is shaped by culture, but it is primarily grounded in one's own experiences in life as well as in universal human values. Each person thus deserves to be respected and valued in her uniqueness and this applies also to research settings, where personal and cultural sensitivity are equally needed" [35].

Talking about culture-sensitivity and bioethics, bioethicist such as Callahan (2004) is of the view that researchers must always endeavor to accord utmost respect to their research subjects which includes appreciating their customs and traditions. The argument is that since each person and each culture finds its own dignity within its own cultural identity, if cultural identities are properly understood and respected, this will offer new ways of doing bioethics [36]. Going by Callahan's viewpoint, "the most benefit is derived when bioethics discipline is employed within historical, ideological, social and cultural contexts" [36]. This is because cultural differences must be taken into account in bioethics especially in research settings that involve securing first person voluntary informed consent from research subjects. Speaking in the same vein, Gbadegesin (2001) opines that every culture, (even the most traditional one) must develop a response to the new technologies in health care systems be it a positive or negative response to these technologies with their consequences. Accepting or rejecting these technologies may be based on traditional norms or on a modification of those norms in the face of the requirements of the new technologies. Bioethics, therefore, requires from each culture, a response to new technologies [37].

Although Gbadegesin calls for a trans-cultural bioethics, a bioethics that is not specific to any single culture, but forms an arena of discussion in which people from diverse cultures can all take part on an equal footing each culture and religion with its own ethical perspectives, must be respected and appreciated [37]. Seibert and others (2002) see the need to be sensitive to the individuallity of different cultural groups. This individuality is expressed in behavior, attitudes, religion and the interpretation of life events [38]. This requirement becomes more paramount when consent is required from vulnerable subjects such as women. Hindrance to the assertion of their autonomy in terms of further restrictions to their ability to give first person voluntary informed consent on the basis of their marital status potentially exposes them to further vulnerability [39].

\section{CAN AUTONOMY BE RELATIONAL IN RESEARCH?}

Conventional models of autonomy have been criticized for presenting a weak and distorted conception of autonomy, over-emphasizing individual rights, paying insufficient attention to wider social context and most especially, focusing too narrowly on the self as independent and rationally controlling [40]. Though criticisms emerge from different starting points, critics share the common resentment of the association of autonomy with a particular brand of individualism often associated with the liberal paradigm. As observed by Bhikhu Parekh (1992), liberalism traditionally defines the individual in "minimalist" terms. "It abstracts the person from all his or her 'contingent' and 'external' relations with other people and nature, and defines the person as an essentially self-contained and solitary being encapsulated in and unambiguously marked off from, the 'outside' world by his or her body" [41].

Similarly, Lorraine Code (1991) views the autonomous person as one who should be self-sufficient, independent, and self-reliant. Such person is a self-realizing individual who directs his efforts towards ensuring that personal gains are maximized. "His independence is under constant threat from other equally self-serving individuals: hence he devises rules to protect himself from intrusion. As a result, talk of rights, rational self-interest, expedience and efficacy permeates his moral, social and political discourse" [42].

Consequent upon this gradual alignment of autonomy with individualism, Meyer (1989) and Calhoun (1992) criticize the status that the Western tradition has granted autonomy. Meyer for instance explains that the notion of 
free agency is flawed because the free agent is assumed to be untainted by socializations. For Meyer, the "true self" is not the stagnant, transcendent, asocial core assumed in most autonomy theories. Rather, the self is dynamic; autonomous people shape their selves through a social mechanism [43]. Similarly, Calhoun (1992) criticizes the kind of self that is associated with autonomy. According to Calhoun, "a model of autonomy that conceives the self as free and independent, bound only by those rules one has given oneself, obligated only by those relationships one has freely entered into, is abstract, empty and unrealizable” [44].

Central to these two viewpoints is the claim that autonomy need not be understood individualistically. Although autonomy has been thought of as the pinnacle of human achievement, the source of human dignity and the mark of moral maturity, the capacity to form and maintain relationships, which has received little attention in the Western philosophical tradition, is arguably just as much of an achievement as autonomy and just as important for moral maturity. Autonomy is one human good and the ability to make and sustain connections with others is another; both are necessary for a rich and complete human life.

For critics such as Keller (1997), the Western conception of autonomy would have to be reconciled with an understanding of the self as relational, feasible within the sphere of interpersonal relations, and compatible with a more differentiated conception of moral life [45]. Keller is skeptical of the central tenet of autonomy in which autonomy has been thought to be possible to the extent that we are able to overcome our socialization and social context and act in accordance with what our "authentic selves” really wants. This asocial understanding of autonomy becomes problematic once we take as our starting point, the relational conception of the self as immersed in and constituted by its relation.

Giving the above problematic understanding of the self, the choice is between abandoning the possibility of achieving autonomy viewing it as illusory or re-conceiving autonomy such that it can take into account its social conditions. The second option is explored in this work in which the research subject/participant conceives of herself/himself as relational and thinks about the world around her/him in terms of the relationships in which he/she is involved. Hence individuals are socially constituted and relationship-oriented.

Pointedly, much of the debate about notions of relational autonomy emerges out of the insights put forward by a particular strand of feminist criticism referred to as the relational approach to autonomy. Relational conceptions of autonomy attempt to take into account the social aspect of autonomous agency which also extends to those views that incorporate not merely causally, but constitutively necessary relational conditions and incurporate a condition that has the form (Rel Agency). A necessary condition for autonomous agency therefore, is that the agent stands in social relations [46].

Many feminists have sought to revise individualistic or atomistic conceptions of autonomy through ideas of "relational autonomy". Relational autonomy is the convictions that persons are socially embedded and that their identities are formed within the context of social relationships and shaped by a complex of intersecting social determinants, such as race, class, gender, and ethnicity. A relational understanding of autonomy means a shift away from oldest views focused on individuals achieving independence towards a view that seeks meaningful selfdirection within the context of interdependence [47].

Lending credence to Beauchamp and Childress's views, MacDonald (2006) opines that a relational critique of autonomy reveals that autonomous individuals must not be conceived in an overly abstract, self-maximizing, atomistic manner. Autonomy must be understood as social in nature and contingent and or processual in practice [48]. Autonomy is about agency and that agency is always exercised by an embedded self. "Others” will always be part of the exercise of one's agency in some form or the other.

MacDonald identifies some characteristics often associated with a relational account of autonomy. First, a relational perspective demands a contextual and dynamic conception of the agent exercising autonomy. Such a conception requires acknowledging that both the agent and his relationship with the external context will undergo constant change that will affect the agent's capacity for autonomy on an ongoing basis. Secondly, a relational perspective demands an account of autonomy that goes beyond conceiving collective forces external to the autonomous agent simply as threat to be contained or barricaded against. Rather than assuming and reinforcing the oppositional nature of such interactions, a relational account of autonomy insists that dependence must be transformed to allow for relationships which are interdependent yet balanced in regard to power and agency during interaction. This makes a relational account of autonomy a politically active account of autonomy [48].

However, a relational approach to autonomy stresses that contrary to certain conceptualizations of freedom and liberty, we cannot simply guard against the influence of others as these circumstances will never be entirely possible. Pretending that one can eliminate these influences not only puts some at a disadvantage, it also overlooks the possibility that these influences may be valuable to the autonomous individual. As noted by Nedelsky (1989):

There is a real and enduring tension between the individual and the collective and any good political system 
will recognize it. The problem with our tradition is that it not only recognizes, but highlights the tension and has a limited view of the non-oppositional aspects of the relation and the social dimension of human beings. The collective is not simply a threat to the individuals but is something constitutive of them and thus is a source of autonomy as well as a danger to it. The task then is to think of autonomy in terms of the forms of human interactions in which it will develop and flourish [49].

For Nedelsky, autonomy must be reconceived as a participatory capacity that does not deny dependence but may work to transform it. Autonomy is not about trying to keep others out so much as ensuring that individuals are effectively empowered when interacting with one another [49]. Autonomy becomes a problem within the state when individuals are shielded from the collective and legal barriers are set around individuals which the state cannot cross. The social context according to Nadelsky cannot simply mean that individuals will encounter one another. It means rather that there are no human beings in the absence of relations with others. Our social being is partly taken from those relations.

It is important to stress that theorists of relational autonomy do not intend to dispense with the notion of autonomy but rather to expand it. By emphasizing the social and historical contexts in which agents are embedded and analyzing the way in which these contexts impede or enhance the capacity for autonomy, advocates of relational notions of autonomy highlight the need for a more "fine-grained and richer account of the autonomous agent” [50].

Another feminist, Evelyn Fox Keller (1985) is of the opinion that autonomy should be dynamic rather than static. According to Keller, "dynamic autonomy develops from the capacity to both relate to and differentiate from others. One develops agency and a sense of self but always in the context of interacting and interpersonal agents" [51]. She contrasts dynamic autonomy with static autonomy which emphasizes the capacity to deny connectedness and enhance separation. The static conception positions "others" and forms of dependency as threats to individual autonomy. On the dynamic perspective, practicing autonomy is a process, an ongoing process that is constantly changing and adapting in relation to the ever changing surrounding context [51].

Andrea C. Westlund (2010) gave reasons why autonomy should be relational. According to her, ahistorical, atomistic self is not a very good reflection of people in the world. Also, autonomy is made possible and maintained only through forms of dependence and interaction with others. Finally, autonomous agents can only learn to be autonomous within a social setting. Therefore, if autonomy exists at all, it must develop from within social systems of interaction with others for the autonomous human is inescapably constituted through relational networks [52].

\section{CONCLUSION REMARKS}

In many African cultural settings, the authority a woman has to give consent to participate or refuse to participate in research belongs to her family especially her husband. It is against this background that this work has examined the Western conception of autonomy. It argued that this conception is too individualistic to be applied in research settings in Africa and in religions such as Islam. The paper looked at what obtains in Ghana and Nigeria as secular countries and some Islamic parts of Pakistan and India. It highlighted certain factors that limit the autonomy of women in these countries stressing at the same time that in spite of these factors, the Western conception of autonomy focuses too narrowly on the self as independent and rationally controlling. The paper questioned the model of an independent, rational will that is inattentive to emotions, communal life, reciprocity and the development of persons over time. It tried to show that theories that focus on autonomous agents and actions seem unrealistic.

The paper called for a more robust account of autonomy which takes cognizance of the social nature of autonomy and recognizes the fact that Africans understand human beings as beings living in natural (appropriate) human relations such as husband-wife, parent-child and brother-sister. Such relations according to Ruiping Fan (2006) are existential rather than contractarian; it forms the living condition of humans and generates certain natural and moral obligations binding everyone, whether or not they agree. Such account also emphasizes the model of a rational will that is attentive to emotions, communal life, reciprocity and the development of persons over time [53]. To sum up however, it is evident from the discussion thus far that respect for autonomy is problematic in settings with concepts of autonomy that differ from Western ideals. For International research therefore, women's autonomy to consent to participate or not to participate in research still remains a contentious issue.

\section{REFERENCES}

[1] Beauchamp, T.L. and Childress, J.F. (2001) Principles of biomedical ethics. 5th Edition, Oxford University Press, Oxford, 59.

[2] MacKenzie, C. and Natalie, S. (2000) Relational autonomy: Feminist perspectives on autonomy agency and the social self. Oxford University Press, New York, 4-5.

[3] Dyson, T. and Moore, M. (1983) On the kinship structure, female autonomy and demographic behaviour in India. Population and Development Review, 9 , 35-60. doi:10.2307/1972894 
[4] Dixon (1978) Rural women at work: Strategies for development in South Asia. John Hopkins University Press, Baltimore, 6.

[5] Beauchamp, T.L. and Childress, J.F. (2001) Principles of biomedical ethics. 5th Edition, Oxford University Press, Oxford, 63.

[6] Childress, J.F. (1990) The Place of autonomy in bioethics. The Hastings Centre Report, 20, 12-17. doi:10.2307/3562967

[7] Dworkin, G. (1976) Autonomy and behaviour control. The Hastings Centre Report, 6, 23-28. doi:10.2307/3560358

[8] Yezzi, R. (1980) Medical ethics: Thinking about unavoidable questions. Holt, Rinehart and Winston, New York.

[9] Friedman, M. (2003) Autonomy, gender and politics. Oxford University Press, Oxford, 45. doi:10.1093/0195138503.001.0001

[10] Churchill, L.R. (2005) Toward a more robust autonomy: Revisiting the belmont report. In: Childress, J.F, Meslin, E. and Shapiro, H., Eds., Belmont Revisited: Ethical Principles for Research with Human Subjects, Georgetown University Press, Washington DC, 118.

[11] Kant, I. (1959) Foundations of the metaphysics of morals, trans. Lewis White Beck, Indianapolis.

[12] Schneider, A. (2010) Kantian Ethics: What Immanuel Kant was talking about. www.helium.com/items

[13] Mill, J.S. (1806-1873) The context in America. Harper's New Monthly Magazine, 24, 683-684.

[14] David, B. and Resnik, J.D. (2010) What is research ethics and why is it important?

http://www.niehs.nih.gov/research/resources/bioethics/wh atis.cfm

[15] Shamoo, A. and Resnik, D. (2009) Responsible conduct of research, 2nd Edition, Oxford University Press, New York. doi:10.1093/acprof:oso/9780195368246.001.0001

[16] Gould, C. (1983) Beyond domination: New perspectives on women and philosophy. Littlefield Adams, Toronto, 14.

[17] Omonzejele, P.F. (2008) African women as clinical research subjects: Unaddressed issue in global bioethics, Ethno-Medicine, 2, 121-126.

[18] Tarisayi (2002) African gender in Zimbabwe. Critical Gender Discourse in Africa, Hope Publications, Ibadan, 123.

[19] Omonzejele, P.F. (2008) African women as clinical research subjects: Unaddressed issue in global bioethics, EthnoMedicine, 2, 123.

[20] Tindana, P.O., Kass, N. and Akweongo, P. (2006) The Informed consent process in a rural African setting: A case study of the Kassena-Nankana district of northern Ghana. IRB: Ethics and Human Research, 28, 1-6.

[21] Hashim, I. (1999) Reconciling islam and feminism. Gender and Development, 7, 7-14. doi:10.1080/741922938

[22] Offenhauer, P. (2005) Women in Islamic societies: A selected review of social scientific literature, a report prepared by the federal research division. Library Research Division, Washington, DC.
[23] Jejeebhoy, S.J. and Sathar, Z.A. (2001) Women’s autonomy in India and Pakistan: The influence of religion and region. Population and Development Review, 27, 687-712. doi:10.1111/j.1728-4457.2001.00687.x

[24] Jejeebhoy, S.J. and Sathar, Z.A. (2001) Women's autonomy in India and Pakistan: The Influence of religion and region. Population and Development Review, 27, 68.

[25] Shaheed, F. (1995) Networking for Change: The role of women's group in initiating dialogue on women's issues. In: Afkhami, M., Ed., Faith and Freedom: Women's Human Rights in the Muslim World, I.B. Taurus, London and New York.

[26] Bhatty, Z. (1993) Socio-economic status of muslim women. Indian Journal of Social Science, 7, 335-340.

[27] Omonzejele, P.F. (2008) African women as clinical research subjects: Unaddressed issue in global bioethics. Ethno-Medicine, 2, 124.

[28] Hashim, I. (1999) Reconciling islam and feminism. Gender and Development, 7, 11. doi:10.1080/741922938

[29] An-Naim, A. (1995) The dichotomy between religious and secular discourse in Islamic societies. In: Afkhami, M., Ed., Faith and Freedom: Women's Human Rights in the Muslim World, I.B. Taurus, London and New York.

[30] Afkhami, M. (1997) Promoting women's rights in the Muslim world. Journal of Democracy, 8, 157-166. doi:10.1353/jod.1997.0015

[31] Olweny, C. (1994) The ethics and conduct of cross-cultural research in developing countries. Psycho-oncology, 3, 1120. doi:10.1002/pon.2960030104

[32] Fisher, N.L. (1996) Cultural and ethnic diversity: A guide for genetic professionals. John Hopkins University Press, Baltimore.

[33] Kagawa-Singer, M. (2003) A strategy to reduce crosscultural miscommunication and increase the likelihood of improving health outcomes. Academic Medicine, 78, 577587. doi:10.1097/00001888-200306000-00006

[34] Kagawa-Singer, M. and Blackhall, I.J. (2001) Negotiating cross-cultural issues at the end of life. JAMA, 286, 29933001. doi:10.1001/jama.286.23.2993

[35] Surbone, A. (2004) Cultural Competence, Why? Annals of Oncology, 15, 689-699. doi:10.1093/annonc/mdh194

[36] Callahan, D. (2004) Bioethics. In: Post S.G., Ed., Encyclopedia of Bioethics, 3rd Edition, Macmillan Publishing, New York, 278-287.

[37] Gbadegesin, S. (2001) Bioethics and cultural diversity. In: Kuhse, H. and Singer, P., Eds., A Companion to Bioethics, BlackWell Publishers, Oxford, 24-32.

[38] Seibert, P.S., et al. (2002) A checklist to facilitate cultural awareness and sensitivity, Journal of Medical Ethics, 28, 143-146. doi:10.1136/jme.28.3.143

[39] Omonzejele, P.F. (2008) African women as clinical research subjects: Unaddressed issue in global bioethics. Ethno-Medicine, 2, 124.

[40] Beauchamp, T.L. and Childress, J.F. (2001) Principles of biomedical ethics. 5th Edition, Oxford University Press, Oxford, 60. 
[41] Parekh, B. (1992) The cultural particularity of liberal democracy. Political Studies, XL, 160-175.

[42] Code, L. (1991) What can she know? Feminist theory and the construction of knowledge. Cornell University Press, Ithaca, 67.

[43] Meyers, D.T. (1989) Self, society and personal choice. Columbia University Press, New York.

[44] Calhoun, C. (1992) Emotional work. In: Cole, E.B. and Coultrap-McQuin, S., Eds., Explorations in Feminist Ethics: Theory and Practice, Indiana University Press, Bloomington, 118-129.

[45] Keller, J. (1997) Autonomy, relationality and feminist ethics. Hypatia, 12, 152-164. doi:10.1111/j.1527-2001.1997.tb00024.x

[46] Helroyd, J. (2009) Relational autonomy and paternalistic interventions. Res Publica, 15.

[47] Beauchamp, T.L. and Childress, J.F. (2001) Principles of biomedical ethics, 5th Edition, Oxford University Press, Oxford, 61.
[48] MacDonald, F. (2006) Relational group autonomy: Ensuring agency and accountability in the group rights paradigm. A paper presented at the Annual Meeting of the Canadian Political Science Association, 6-8.

[49] Nedelsky, J. (1989) Re-conceiving autonomy: Sources, thoughts and possibilities. Yale Journal of Law and Feminism, 1, 7-36.

[50] MacKenzie, C. and Natalie, S. (2000) Relational autonomy: Feminist perspectives on autonomy agency and the social self. Oxford University Press, New York.

[51] Keller, F. (1985) Reflections on gender and science. Yale University Press, New Haven, 96-97.

[52] Westlund, A.C. (2010) Rethinking relational autonomy. http://pantherfile.uwm.edu/westlund/www.rra

[53] Fan, R. (2006) Bioethics: Globalization. Communitization or localization. In: Engelhardt, H.Y., Ed., Global Bioethics: The Collapse of Consensus. $\mathrm{M}$ and $\mathrm{M}$ Scrivener Press, 271-299. 